\title{
PERFIL DE FORMACIÓN DEL FUTURO PROFESIONAL DE TERAPIA OCUPACIONAL
}

\author{
Universidad Colegio Mayor de Nuestra Señora del Rosario \\ María Eugenia Caicedo C. \\ OCTUBRE DE 1997
}

Me resulta difícil ubicar el perfil de formación del futuro terapeuta ocupacional, sin reflexionar un poco acerca de su papel y su recorrido hasta el momento. La prospección debe hacerse sin desconocer los esfuerzos previos realizados.

Muchas cosas han ocurrido desde que la Asociación Colombiana de Terapia Ocupacional se hizo realidad el 5 de Junio de 1972, gracias al esfuerzo de sus socios fundadores quienes creyeron que era necesario dotar a la profesión de un escenario propio que impulsara y reflejara el crecimiento de los profesionales de la Terapia Ocupacional.

En 1974 hicimos nuestra primera publicación donde definíamos la Terapia Ocupacional como una «técnica terapéutica en la cual, con base en la prescripción médica y a través de la valoración cuidadosa del paciente, se utilizan actividades físicas o mentales que profesionalmente guiadas van a favorecer el desarrollo, la recuperación u obtención de los potenciales físicos y psicosociales, que le permiten (a la persona) rehabilitarse e integrarse como individuo productivo a la sociedad y le brindan la posibilidad de adaptarse, comunicarse y establecer relaciones interpersonales». Se destacaban entonces las actividades terapéuticas como medio para obtener la recuperación de habilidades perdidas como consecuencia de problemas de salud temporales o permanentes.

Hoy la Terapia Ocupacional se define como la profesión que estudia la naturaleza ocupacional del hombre que se manifiesta en su desempeño.

La ocupación como transformadora del hombre y su cultura, está presente y es cambiante durante toda la vida y se explícita en la interacción entre las características personales y las del contexto (esta definición fue construida de manera colectiva en la reunión convocada por el ICFES y la ACTO 
entre el 12 y el 14 de Noviembre de 1997). Se destacan aquí el conocimiento de la ocupación humana como objeto de estudio y su importancia para la vida personal y para el contexto cultural.

A través de las revistas de la ACTO que se volvieron sistemáticas 10 años después en 1984, puede seguirse la evolución de las Terapia Ocupacional y de sus profesionales en el país. De una publicación de corte técnico, la discusión se ha tornado cada vez más científica y especializada; es notorio observar con el tiempo además que las referencias aluden cada vez más a colegas nacionales y como la Terapia Ocupacional adquiere un perfil más colombiano, que le permite a nuestros profesionales de hoy prestar servicios en salud, en rehabilitación, en trabajo, en comunidad y con poblaciones marginales, en situaciones muy relacionadas con nuestro propio contexto cultural. Además contamos con terapeutas desempeñándose con éxito en administración, en docencia y en investigación.

Aunque muchas cosas han cambiado, se ha definido cada vez más el aspecto nuclear. La ocupación se ha ido perfilando no sólo como objeto de estudio o modelo sino como ciencia social que permite organizar los fenómenos de una manera propia, que cuenta con un sistema general de teoría que dio sus primeros pasos en los años 80 con la propuesta del Modelo de Ocupación Humana de Kielhofner y Burke apoyados en los estudios anteriores de Really. Por eso me parece que a los terapeutas'ocupacionales del futuro, les será más sencillo adquirir identidad profesional.

Los terapeutas ocupacionales que hoy formamos ya no tienen que buscar sino fortalecer sus esquemas de pensamiento alrededor de su objeto de estudio pero en cambio deben enfrentar tres desafios fundamentales:

* Las nuevas concepciones de educación y de currículo

* La situación de país.

* Los desarrollos de la Ocupación.

\section{LAS NUEVAS CONCEPCIONES DE EDUCACIÓNY DE CURRÍCULO}

La Ley 30 significó para las Universidades no sólo la confirmación de la autonomía universitaria, es más que el desafío de la autoevaluación y de la acreditación con pares académicos, conlleva replantearse la misma Insti- 
tución y el currículo para garantizar la pertenencia social y la pertinencia académica de los programas.

El currículo es nuevamente el centro de la reflexión como un proceso permanente más allá de lo formal y no como una mera clasificación de conocimientos en asignaturas más o menos especializadas e interdisciplinares que se utilizan por parte del estudiante en una acción instrumental y que le permiten a la institución mantener un control administrativo del cumplimiento de objetivos previamente determinados.

El nuevo desafío le implica a quienes estamos comprometidos en la Educación Superior, facilitar al educando organizar su conocimiento en torno a la solución de problemas que obviamente superan los límites disciplinares; implica una conexión permanente entre lo experiencial y lo teórico rescatando otra vez el valor de lo empírico; produce núcleos de investigación permanentes y en general que el currículo sea un proceso, no un producto terminado.

Todo esto dentro del marco de la internacionalización y globalización que imponen por lo menos el manejo de una segunda lengua y la utilización solvente de los adelantos tecnológicos en información.

Nuestros estudiantes ya no deben responder a la simple acumulación de información sino que desde el principio deben plantearse posibles explicaciones, volver a la actitud crítica que no ofrece certezas e ir más allá de la descripción organizada de datos; se le pide plantear nuevos problemas y trabajar realmente de manera interdisciplinaria donde lo aparentemente seguro y cierto puede desaparecer.

Además de eso enfrenta nuevamente al maestro con su función de formación en valores, con la necesidad de ser ejemplo y orientador de los estudiantes y al estudiante con su responsabilidad personal y social de construir un proyecto de vida en que el servicio juegue un papel primordial.

Esto constituye un desafio desde el punto de vista educativo, pero permitirá a nuestro estudiante del futuro cargar de sentido desde el primer momento los fenómenos a los cuales se enfrenta, a la disciplina confrontarse interdisciplinariamente y a las instituciones caracterizar sus programas. 


\section{LA SITUACIÓN DEL PAÍS}

Como parte del criterio de pertenencia social, los programas pueden ser adaptados en sus aspectos esenciales a otros contextos, pero deberían responder primariamente al contexto que los genera.

Es aquí donde el nuevo ordenamiento jurídico - que rige al país desde 1991 - cobra especial importancia. Se ha dado lugar a la Ley 100 de Seguridad Social que desestimula el ejercicio de la consulta privada en salud, pero promete nuevos campos en promoción y prevención, refuerza su importancia en Salud Ocupacional, le recuerda que es muy importante en Rehabilitación Profesional e imprescindible en Salud Mental.

Con respecto a la Ley 115 General de Educación ocurre algo semejante, cuando se desestimula la Educación Especial pero se solicitan equipos de especialistas de apoyo, se promueve la intervención en la escuela regular de todos los que aporten al mejor desarrollo infantil, el juego tiene una posición privilegiada para facilitar al niño los logros futuros, adquieren relevancia lás materias vocácionales y en general se amplía el espectro para trabajar conjuntamente con el maestro.

La Ley 182 del Deporte consagra no sólo la actividad de alto rendimiento sino que promueve la recreación, las actividades de ocio, como medio fundamental para mejorar la convivencia ciudadana.

Podríamos continuar hablando de otras leyes, pero todo lo que quiero señalar es que esta organización social abre nuevas perspectivas de desempeño al terapeuta y que es importante identificarlas porque son los campos de acción del terapeuta del futuro.

Sin embargo la realidad del país, a la que deben corresponder los programas, es mucho más compleja que lo que señala su organización legal y en ese sentido, las situaciones de violencia, el desempleo, los desplazados por la violencia, la concentración urbana, la necesidad de formación permanente, los nuevos perfiles profesionales, suponen desafios que deben enfrentar también los terapeutas ocupacionales que estamos formando. 


\section{LOS DESARROLLOS DE LA OCUPACIÓN}

Por último me gustaría tocar este tema fundamental. Como señalé en un principio, muchos cambios han ocurrido en la profesión desde que pensamos en que el terapeuta ocupacional podía guiar una serie de actividades con propósito pero comprendidas y analizadas a través de esquemas de pensamiento de otras disciplinas, hasta ahora se reconoce que la ocupación podría ofrecer sus propios esquemas explicativos como lo hacen otras ciencias como la antropología, la psicología o la educación.

En este sentido hay mucho que aprender e investigar, la Universidad debe adquirir de nuevo supremacía en investigación no sólo en la aplicación de esquemas y de técnicas sino en la generación de conocimiento alrededor de la Ocupación como única manera de proveer esquemas de análisis al estudiante que aseguren una ubicación y una relevancia social en un panorama laboral siempre cambiante.

La Universidad debe ser además el lazo entre las perspectivas del futuro y las raíces, la que permitirá no olvidar que somos una profesión de servicio, que los desarrollos científicos y tecnológicos debierán estar siempre en función de quienes nos necesitan, que es fundamental que adaptemos tanto los desarrollos en materia de ocupación como de tecnologías a las necesidades y posibilidades de los colombianos.

Así puede verse con claridad como la Universidad y la ACTO se articulan para que el estudiante del futuro logre la actualización permanente que requiere, para que la academia y el mundo del trabajo actúen de manera consecuente y para que la actitud crítica social que le corresponde a las Universidades se base en las situaciones reales que viven sus egresados. 